\title{
分子配向膜の高速測定法
}

\author{
田ノ岡大輔 \\ (诛モモリテックス７225-0012＼cjkstart神奈川県横浜市青葉区あざみ野南 1-3-3
}

\section{High-Speed Measurement Method for Molecular Orientation of Thin Films}

\section{Daisuke Tanooka}

MORITEX CORPORATION

1-3-3, Azaminominami, Aoba-ku, Yokohama 225-0012, Japan

For higher performance of organic thin film devices, the molecular orientation control is important. We developed the method and instrument to evaluate molecular orientation of thin films. This method provides the direction and size of the refractive-index anisotropy by the molecular orientation. It has advantages of the high detection resolution of anisotropy and the high-speed measurement. We demonstrated the performance of this instrument by measuring the alignment films for liquid crystal display devices.

Key words : molecular orientation $/$ organic thin film $/$ anisotropy $/$ alignment layer film

\section{1. はじめに}

近年, 液晶，有機 $\mathrm{EL} ，$ 有機トランジスタといった 有機薄膜を用いた電子デバイスが実用化，あるいは 実用化へ向けて活発な研究, 開発が行われている. 有機薄膜は無機薄膜に比べて, 低コストに大面積処 理が可能であり，また新規分子構造による性能向上 の可能性があるという優位性がある.

有機薄膜デバイスがより高い性能を持つには，そ の分子配向制御が重要であると言われている ${ }^{1}$. 分子 配向評価の測定方法として, 赤外分光法, 偏光解析 法, SHG 法, X線回折法が広く用いられている.こ れらは, 強力な測定方法であるが, 測定が煩雑であ る，あるいは測定に時間がかかるという問題がある. 我々は, 研究, 開発だけでなく製品の検査や不良解 析など生産に近い現場でも分子配向測定が行えるよ う, 試料や装置の扱いが簡便であり, 短時間で配向 測定が可能な測定手法と装置（製品名：LayScan）を

Tel : 045-913-5149 Fax : 045-913-5332

E-mail : dt0868@moritex.co.jp
考案, 開発した. 以下, その測定原理と液晶配向膜 による測定例について述べる.

\section{2. 測定原理}

分子配向した有機薄膜は光学異方性（屈折率異方 性）を持つ. 光学異方性をもつ物質に対して, 入射 面に対して平行な振動方向をもつ光 ( $\mathrm{P}$ 偏光), ある いは入射面に対して, 垂直な振動方向をもつ光 (S偏 光）を入射した場合, 相異なる偏光成分を含む光が 反射する. 配向のない（屈折率異方性のない）物質 では, この現象は生じない. LayScanは, この光学異 方性による現象を利用して, 分子配向した有機薄膜 の配向方位角 (面内方向), 傾斜角 (極角方向), 屈 折率異方性の大きさをそれぞれ測定する.

Fig. 1は一軸異方性の屈折率楕円体に対し, 光が長 軸方位すなわち配向方位と平行な方位から入射した 場合を表している. P偏光を入射した場合, Fig. 1で 示されるように波面法線方向の切断面の長軸方向と 光波の振動方向が平行であるため, $\mathrm{P}$ 偏光を入射した 場合の $\mathrm{S}$ 偏光の反射率 $R_{\mathrm{sp}}$ は 0 となる. $\mathrm{S}$ 偏光を入射 


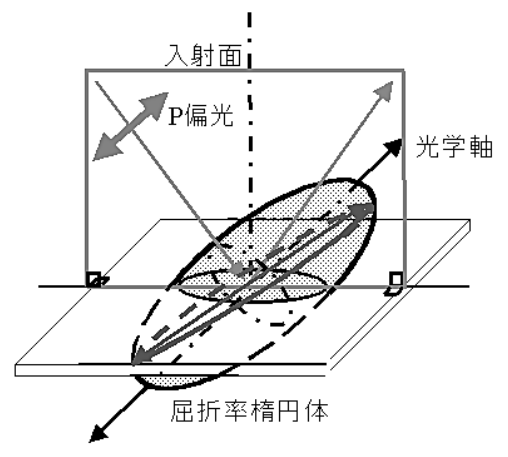

Fig. 1 Light is incident from a parallel direction to the long axis of index ellipsoid.

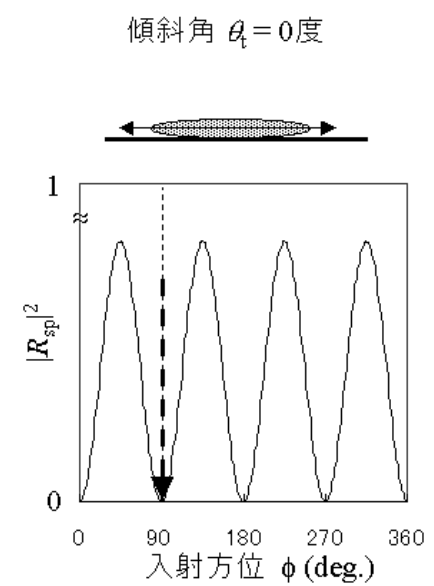

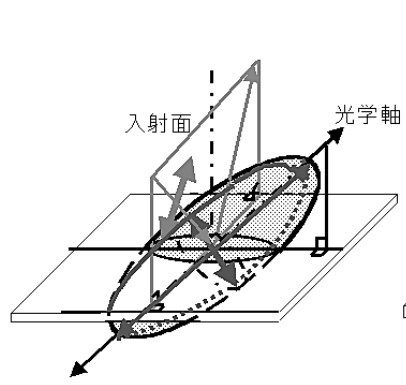

(a) 光が配向方位と直交する方位か ら入射した場合

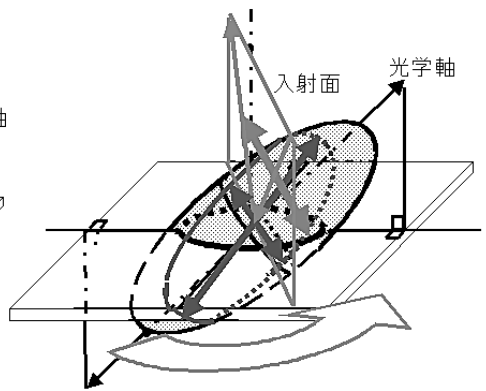

（b）光が直交方位に対してシフトした 方位から入射した場合

Fig. 2 (a) Light is incident from a orthogonal direction to the long axis of index ellipsoid.

(b) Light is incident from a shifted direction.
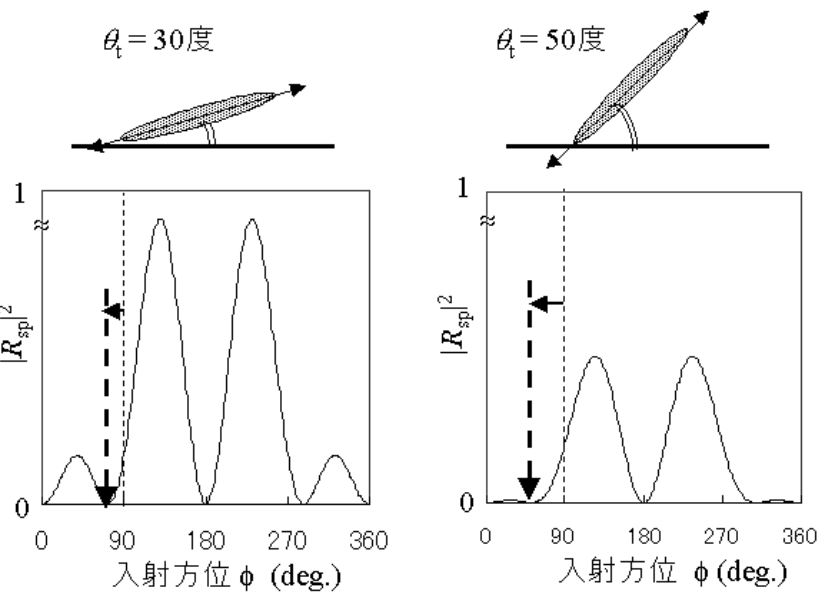

Fig. 3 The results of numerical calculation when changing the tilt angle.

した場合も同様である。したがって，配向方位は $\mathrm{P}$ 偏光，あるいは $\mathrm{S}$ 偏光を入射したとき，相異なる偏 光状態の反射が 0 となる方位から決めることができ る. Fig. 2（a）は配向方位に対して直交する方位か ら P 偏光の光を入射した場合を表している．傾斜角 $\theta_{\mathrm{t}}=0$ の場合, 電場の振動方向と波面法線の垂直切 断面の長軸, 短軸の方向は平行, 直交するため, $R_{\mathrm{sp}}=0$ である. $\theta_{\mathrm{t}} \neq 0$ の場合, 電場の振動方向と波 面法線の垂直切断面の長軸, 短軸の方向は平行, 直 交しないため， $R_{\mathrm{sp}} \neq 0$ である. Fig. 2（b）は直交方 位に対してシフトした方位から $\mathrm{P}$ 偏光の光を入射し た場合を表している.この場合, 電場の振動方向と 波面法線の垂直切断面の短軸の方向は平行に近づく. より平行になったときに, $R_{\mathrm{sp}}$ は最小となる. Fig. 3 は Berremannの $4 \times 4$-Matrix 法 ${ }^{2,3)}$ により $\theta_{\mathrm{t}}=0$, 30, 50 度としたときの数值計算結果である。横軸が 方位, 縦軸は $\left|R_{\mathrm{sp}}\right|^{2}$ である. 傾斜角の増加にしたがっ て, 最小方位がシフトする.これは直交方位近傍で $\left|R_{\mathrm{sp}}\right|^{2}$ が最小となる方位を求めることにより, 傾斜角 が算出可能であることを示している．また， $R_{\mathrm{sp}}$ の大

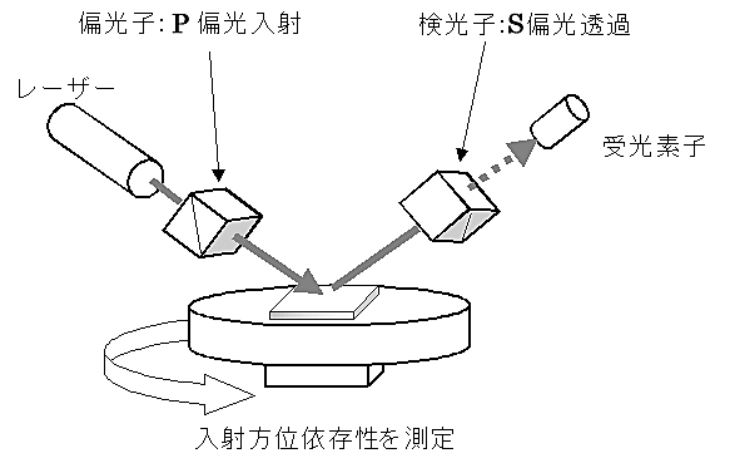

Fig. 4 Schematic of the measurement system.

きさは異方性の大きさ（屈折率差の大きさと異方性 のある層の膜厚）に依存するため， $R_{\mathrm{sp}}$ の大きさから 異方性の大きさを見積もることができる.

Fig. 4, 5 は, 装置構成の簡略図と装置本体の写真で ある. 入射偏光状態を $\mathrm{P}$ 偏光となるように, 偏光子 の方位を設定する. それに対し, 検光子の方位は $\mathrm{S}$ 偏光が透過するようにする. この状態で, 受光強度 の試料方位依存性を測定し, 配向方位, 傾斜角, 異 


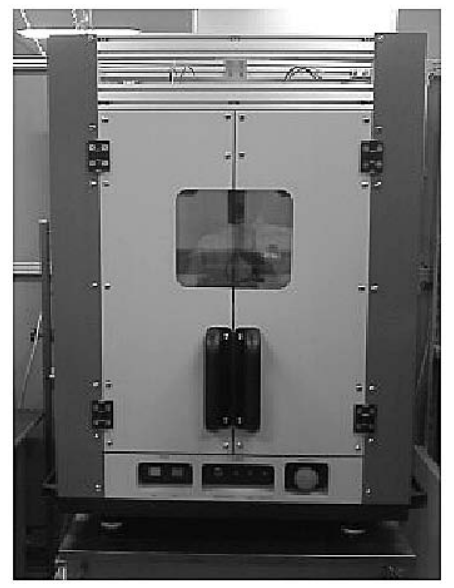

Fig. 5 Picture of the measurement instrument.

ラビング処理

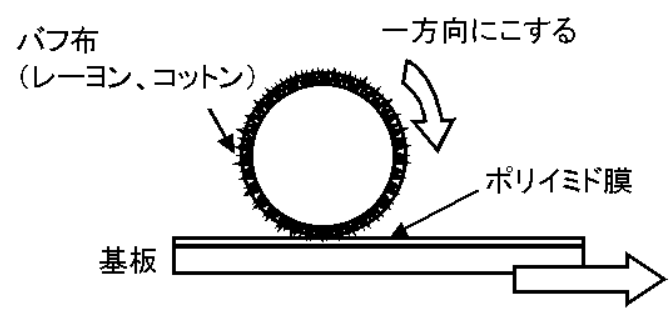

Fig. 6 Manufacture method of an alignment layer films for liquid crystal display devices.

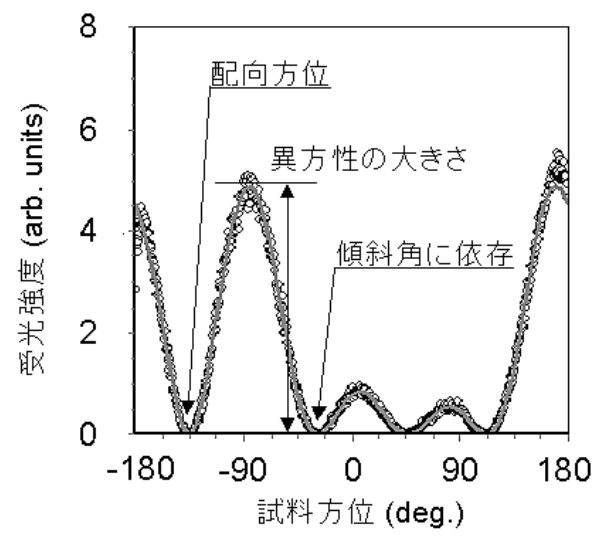

Fig. 7 Measurement data of an alignment layer film for liquid crystal display devices.

方性の大きさの測定を行う.

\section{3. 測定例：液晶配向膜の配向測定}

液晶配向膜は液晶表示素子 (Liquid Crystal Display devices: LCD）において液晶分子の初期配向を決定す るために用いられており, 液晶配向膜の配向処理の 良否が製品の良否に影響を与える。液晶配向膜の配 向方位, 傾斜角, 異方性の大きさ（分子固有の複屈 (a)

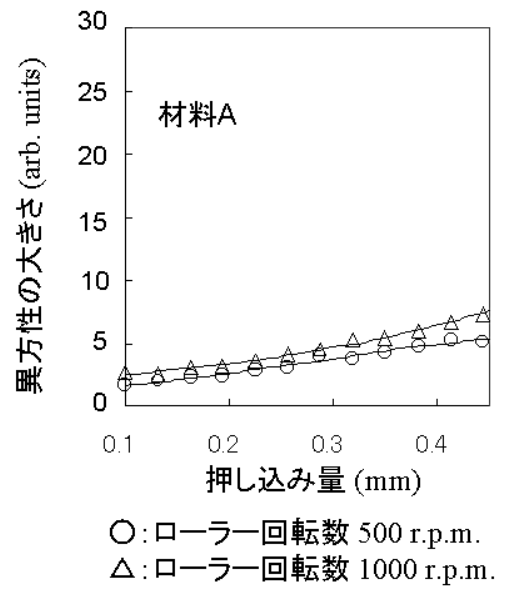

(b)

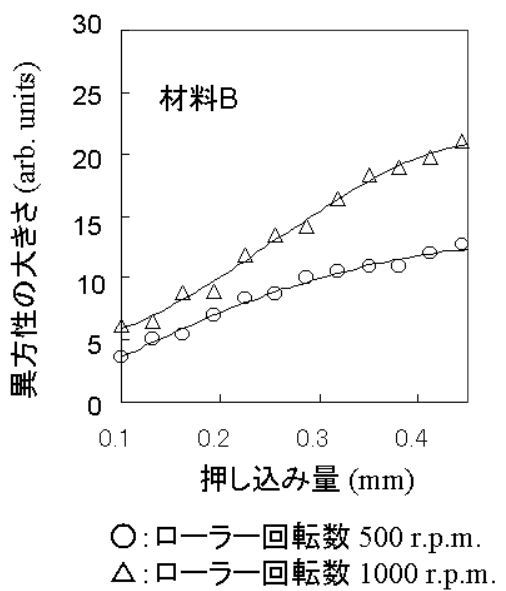

Fig. 8 (a), (b) : Measurement results of anisotropy in different conditions of the material and the rubbing process.

折と配向度の積）は, 液晶分子の面内方向の向き, 液晶分子の極角方向の傾き（プレチルト角：電界を かけた時, 液晶分子が逆方向から立ち上がるのを防 ぐ，液晶分子への規制力（液晶分子の向きを揃える 力）をそれぞれ決定する.したがって, 液晶配向膜 の配向評価は LCD の開発や生産性の向上のために重 要である.

Fig. 6 は液晶配向膜の一般的な作製方法の模式図で ある，基板上にポリイミドを塗布，焼成した後，布 で擦る配向処理（ラビング）を行う。ラビング処理 を行った配向膜上に液晶分子を接触させると, 液晶 分子は配向膜分子との分子間力により並ぶことが知 られている ${ }^{4)}$.この配向処理方法は生産性が高く, 製 造コストが低いため, 生産工程で広く用いられてい る. ラビング処理で作製した配向膜は, 全体の厚さ 
(a)

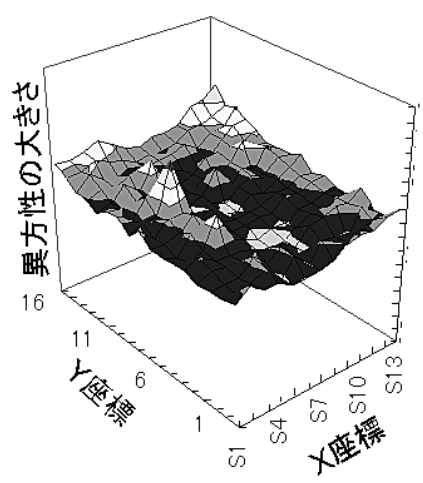

(b)

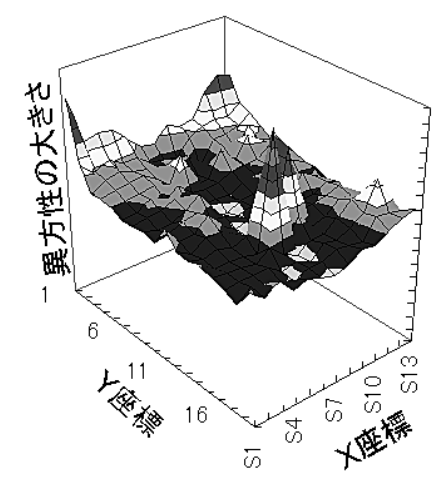

Fig. 9 (a) Measurement result of in-plane distribution of anisotropy.

(b) Measurement result of the $90^{\circ}$ rotation placement of the sample.

が 50 ～ $150 \mathrm{~nm}$ 程度，配向している層の厚さが 5 〜 20 $\mathrm{nm}$ 程度, 常光と異常光の屈折率差が 0.01 程度である. この程度の小さな複屈折を測定する必要があるため, 測定は高い検出能力が必要である.

Fig. 7 は，標準的な液晶配向膜の LayScan による測 定データである，丸点が測定データ，実線がフィッ ティングデータである．配向方位を意味する大きな 2 つの山の間の谷の方位, 傾斜角の大きさに依存する 大きな山と小さな山の間の谷の方位, 異方性の大き さを意味する大きな山のピーク值，どれも明確に測 定できていることが分かる.

Fig. 8 は，分子構造の異なるポリイミド薄膜を異な るラビング条件で配向処理したときの異方性の大き さの測定結果である．ローラー回転数はラビング布 を巻いているローラーの1分間あたりの回転数, 押し 达み量は，布を基板方向に押し込む量を意味する. 配向膜材料, 配向処理によって異方性の大きさが変 化していることが分かる.

ラビング処理は, 布で擦るという粗い処理のため, 配向ムラが生じやすいという問題がある．配向ムラ
を評価するには, 分布測定が必要である. LayScanは, 一点あたり測定時間 20 秒以下で測定できるため, 分 布測定が可能である. Fig. 9（a）は標準的なラビン グ処理を行った試料の異方性の大きさの分布測定の 結果である. 場所によって, 異方性の大きさが異な っていることが分かる．この結果が, 試料の配向ム ラを示していることを確認するために，装置に対す る試料配置を 90 度回転して測定したときの結果が Fig. 9（b）である. 異方性の大きさの分布が試料配 置に追従しており，この分布が確かに配向分布であ ることを示している.これは, 分子配向の分布評価 にも LayScanが有効であることを示している.

\section{4. まとめ}

分子配向した有機薄膜評価のための測定方法およ び装置と測定例の紹介を行った。本装置は, 分子配 向の配向方向, 傾斜角, 異方性の大きさを高速に高 い検出分解能で測定することができる. 測定例とし て, 液晶配向膜の材料および配向処理に依存したデ ータを示した. 有機薄膜は, 分子配向を制御するこ とにより, 新規機能の発現や機能向上の可能性があ る. 本装置が配向制御による新規デバイスの研究・ 開発の一助を広く担うことができると考えている.

\section{文献}

1）例えば, 内藤裕義, 久保野敦史, 舟橋正浩, 吉本尚起 （監修）：有機エレクトロニクスにおける分子配向技 術, シーエムシー出版 (2007)

2) Berreman DW :J. Opt. Soc. Am, 62, 502-510 (1972)

3) Berreman DW: J. Opt. Soc. Am, 63, 1374-1380 (1973)

4) Geary JM, Goodby JW, Kmetz AR, Patel JS : J. Appl. Phys., 62, 4100-4108 (1987)

(Received 12 April 2008; Accepted 14 April 2008) 